\title{
ENTRE LAS LIBERTADES Y LA SALUD PÚBLICA. LA RESPUESTA DEL GOBIERNO MEXICANO ANTE LA COVID-19
}

\author{
BETWEEN LIBERTIES AND PUBLIC HEALTH. THE MEXICAN \\ GOVERNMENT'S RESPONSE TO COVID-19
}

\author{
Andrea Samaniego Sánchez \\ Eduardo Torres Alonso \\ etorres.alonso@gmail.com
}

Facultad de Ciencias Políticas y Sociales, Universidad Nacional AutónOMA DE MÉXICO, MÉXICO 
Para citar este artículo:

Samaniego Sánchez, A., \& Torres Alonso, E. (2020). Entre las libertades y la salud pública. La respuesta del gobierno mexicano ante la COVID-19. ESPACIO I+D, INNOVACIÓN MÁS DESARROLLO, 9(25). https://doi.org/10.31644/IMASD.25.2020.a07

\section{RESUMEN}

El artículo trata sobre las acciones implementadas por el Estado Mexicano para hacer frente a la emergencia sanitaria ocasionada por la COVID-19, de cara a las investigaciones políticas en la materia y su interpretación basadas en las mismas. Frente a los análisis que indican que, las estrategias implementadas para hacer frente a la emergencia sanitaria, son contrarias a los principios liberales de las democracias. En el caso mexicano, se dan una serie de acciones que también limitan la libertad, pero no hay movilizaciones que cuestionen esas restricciones.

\section{Palabras clave}

Democracia, emergencia sanitaria, COVID 19, restricciones, libertades. 


\section{- Abstract-}

The article studies the actions implemented by the Mexican State to respond the health emergency caused by COVID-I 9 considering political investigations on the matter and their interpretation to the mexican situation. The analyzes indicates that the strategies implemented are contrary to the liberal principles of democracies. In the Mexican case, there are a series of actions that also limit freedom, but there are no mobilizations that question those restrictions.

\section{Keywords}

Democracy, health emergency, COVID 19, restrictions, liberties. 
os gobiernos democráticos se sustentan en las premisas liberales del resguardo y preservación de las libertades individuales para la autorrealización personal y consecución de los fines que cada ciudadano se coloque como propios.

Sin embargo, también existen tentaciones por limitar esas libertades, tales como el discurso de la seguridad y resguardo de la población, que ponen en entredicho los postulados liberales.

En este momento, la emergencia sanitaria ocasionada por el SARSCoV-2 ha creado una serie de respuestas en los Estados del planeta, que deben hacer frente a la amenaza que produce el virus ante su población, respuestas que, al igual que la seguridad, también atentan contra el ejercicio personal de la población.

Los trabajos hechos hasta el momento muestran una tendencia a la reducción de las libertades en aras de la salud pública. Lo que se revisará en el presente trabajo es la acción del gobierno mexicano y, con ello, determinar si se encuentra más cerca de las respuestas de regímenes autoritarios o de democráticos.

\section{LAS DEMOCRACIAS OCCIDENTALES Y EL PRINCIPIO DE LIBERTAD}

De acuerdo con Eric Hobsbawm (1996) existen dos grandes movimientos sociales que generan como resultado el surgimiento de las sociedades contemporáneas: la Revolución Industrial y la Francesa, la primera reivindica la propiedad privada y la libertad del mercado, la segunda el predominio de las libertades individuales, los derechos pro persona y la reivindicación de la soberanía del pueblo como tomador de decisiones en el quehacer de lo político.

Estos dos momentos constituyen el desenlace del pensamiento liberal, la separación de la visión del soberano y el predominio del individuo como gestor de su destino.

Dicho de otro modo, el liberalismo, como corriente de pensamiento, influyó en las acciones de la sociedad y generó que los individuos se supieran libres para organizarse y decidir el pacto de representación que mejor atendiera a sus intereses.

Por ello, la mayoría de los gobiernos, desde el siglo XVIII y hasta la época contemporánea, consideran a la libertad individual uno de los pilares fundamentales de su quehacer cotidiano.

El discurso democrático pareciera que adquirió hegemonía durante el final del siglo XX, en particular con la caída del Muro de Berlín y el desmembramiento de la URSS, con lo cual los proyectos políticos diferentes a las democracias quedaban en un segundo plano, puesto que, si el referente de ese otro orden dejó de existir, difícilmente se podría pensar en un ejercicio político diferente. 
Sin embargo, hay que destacar que existen otras formas de gobierno de corte autoritario, donde el discurso democrático y de las libertades no es concebido porque de lo que se trata es de mantener el orden al interior de esos Estados.

Ahora bien, es en circunstancias excepcionales donde las libertades se ponen en entredicho o se limitan bajo la premisa de que se busca resolver un problema más grande o por la consecución de un bien mayor.

Este fue el discurso propio de principios del siglo XXI, con la caída de las Torres Gemelas en Nueva York, cuando bajo la noción de seguridad y ataque al terrorismo, se limitaron las libertades de los ciudadanos en el entendido de que, la idea de seguridad resguardaba a la sociedad en conjunto y como tal, el beneficio era mayor a aquel que gozaban por el ejercicio de los derechos particulares.

Por ejemplo, con la Ley Patriótica emitida por el presidente de los Estados Unidos, George W. Bush y que fue aprobada por el Legislativo de ese Estado, se restringían las libertades individuales de sus ciudadanos, pues bajo la sospecha de ser terroristas o de colaborar con el terrorismo, ellos podían ser investigados en su propio territorio, esto significa una violación a su privacidad, lo cual, al final, atenta la perspectiva liberal que es pilar fundamental de las sociedades democráticas.

En el caso mexicano, de igual manera, distintas legislaciones buscaban contener las libertades individuales por la consecución de un bien social considerado de mayor importancia. La inseguridad en México y el crecimiento de las bandas de crimen organizado, generan un discurso que legitima la restricción individual.

Por ello, se puede indicar que, si bien el ejercicio de las libertades es uno de los elementos fundamentales de las democracias occidentales, existen también ciertos discursos, que, a los ojos de los gobernantes, justificarían su limitación.

\section{LA CRISIS SANITARIA ORIGINADA POR LA COVID 19}

La emergencia sanitaria derivada por la pandemia del Coronavirus SARSCoV-2 tiene su origen a finales del 2019, cuando en Wuhan, China, detectaron la presencia de una nueva enfermedad, que produce un cuadro de infección respiratoria con tos seca, fiebre y cansancio.

De acuerdo con investigaciones del Imperial College de Londres (2020) se determinó que el índice de reproducción básico Ro, fluctúa entre 1.5 y 3.5 personas (Bravo-García, Ortiz-Pérez. 2020: 7) es decir, cada persona contagiada podría contagiar a su vez desde I.5 personas hasta 3.5 antes de sanar o morir. Hay estimaciones del Centro de Control de Enfermedades en Estados Unidos que calculan el Ro del SARS-Cov-2 en 5.7 lo cual daría 
cuenta de una enfermedad contagiosa (Sanche.Ting, Xu, Romero Severson, Hengartner Ke. 2020). Esto, permite a los gobiernos saber la velocidad de propagación de un virus dentro de su población. (Ridenhour, Kowalik. Shay. 2018: 167) y tomar decisiones en el tema de políticas públicas.

El 23 de enero de 2020, menos de un mes después de haberse detectado la enfermedad COVID-19, el gobierno chino ordenó la primera cuarentena en la provincia de Hubei como medida para evitar la propagación del virus en su territorio.

Para marzo, la OMS declaró al nuevo virus SARS-CoV-2 una pandemia, en un momento donde se tenían contabilizados cerca de 118000 casos en I 4 países, es decir, para ese momento, la enfermedad ya tenía un alcance de carácter planetario.

Con la información que hasta el momento se tiene sobre este nuevo virus, cada Estado ha tomado distintas decisiones para hacer frente a las mismas.

\section{LA RESPUESTA DE LOS GOBIERNOS ANTE LA CRISIS DEL SARS-COV-2}

El estudio de las respuestas gubernamentales en torno a la emergencia sanitaria ocasionada por el virus SARS-CoV-2, ha ocasionado una serie de investigaciones que posibilitan la comprensión sobre el fenómeno. Así, por ejemplo, se han establecido diferencias entre las acciones de los gobiernos democráticos vis-à-vis aquellas de gobiernos autoritarios (Cheibub, Jean, Przeworski. 2020).

En el trabajo de estos autores subsiste una hipótesis central, las democracias tardaron más en responder que los gobiernos autoritarios, puesto que las primeras se preocuparon por la preservación de las libertades individuales, tales como la libertad de reunión, de asociación, de mercado o de credos. Mientras que los autoritarios implementaron todas estas medidas desde el inicio, porque la perspectiva liberal y de resguardo de los derechos individuales no es prioritaria.

Sin embargo, cabe destacar de acuerdo con la investigación que, sin importar el tipo de régimen político, todos llegaron, antes o después, a limitar las libertades: cerrar escuelas, limitar reuniones públicas o cerrar trabajos que no se consideraban esenciales.

También se demuestra que, dentro de las democracias, aquellas que tardaron más en reaccionar, fueron democracias que tienen más tiempo de estar establecidas, por lo que se puede considerar que tienen mayor arraigo con la protección de las libertades fundamentales, mientras que otras no tan recientes o establecidas, pudieran no tener tantos problemas con estas limitantes.

Pero, lo que indican Cheibub, Jean y Przeworski en su escrito es que, algunas de estas restricciones iniciaron nada más llegó la epidemia a cada 
Estado, y, se volvieron cada vez más severas conforme aumentaban el número de muertos en los territorios.

Por otro lado, Cronert (2020) explica cuáles pudieran ser los motivantes para las acciones institucionales implementadas en el marco de la emergencia sanitaria. Para hacerlo, analiza ciertos referentes: efectividad gubernamental y elecciones políticas.

En este sentido, Cronert indica que uno de los resultados hallados es que los gobiernos más eficientes fueron más tardados en responder, que aquellos con aparatos gubernamentales menos eficientes. Además, dice que la acción de los gobiernos pudiera estar mediada por una consideración de tipo política, esto es, si tenían un partido opositor fuerte o no, y si tienen en puerta una elección o no. Con ello se pueden concluir las siguientes observaciones:

I) Para las democracias, la preservación de las libertades fue el elemento central en la acción gubernamental que restringía la acción individual en aras de un bien colectivo.

2) También, dentro de las democracias, aquellas que tienen mayor tradición con este régimen tardaron más en responder, es decir, en limitar las acciones individuales.

3) Muchas de estas democracias antiguas o más tradicionales, tienen la infraestructura sanitaria más desarrollada del mundo, lo que también pudiera explicar el fenómeno, puesto que consideraron tener la capacidad para responder ante el virus.

4) Además, estas democracias tienden a tener sistemas económicos fuertes, con programas que protegen a sus ciudadanos en casos de desempleo. Esto es importante, porque una de las limitaciones que se dieron en torno de esta emergencia fue la del trabajo, en donde solo los esenciales debían salir y laborar.

5) Solo fue cuando se dio una saturación del sistema hospitalario, así como un aumento del número de muertos, que comenzaron a limitar ciertas actividades individuales. Es decir, hay una relación entre número de muertos y limitación de actividades.

6) En las democracias más efectivas, esto es, donde existe una fuerte deliberación sobre los temas públicos, tardaron más en resolver esta emergencia y la estrategia preferente que debía ser implementada. En gobiernos donde, si bien, hay democracia, pero no tanta deliberación o el poder se concentra de forma particular, esta toma de decisión es más sencilla, y por ello, más rápida.

7) Solo en las democracias se consideró el factor de las elecciones políticas, esto porque en los regímenes autoritarios no hay elecciones, y porque esto puede mediar el tipo de acción que se espera de un partido en el gobierno frente a una oposición que desea el poder. 


\section{LAS ACCIONES DEL GOBIERNO FEDERAL MEXICANO POR LA CRISIS SANITARIA DEL SARS-COV-2}

Si bien el virus se detectó a finales del 2019, éste llegó al territorio nacional en el primer trimestre del 2020. En las primeras declaraciones efectuadas en torno al tema, el Doctor Hugo López Gatell, subsecretario de Prevención y Promoción de la Salud de la Secretaría de Salud, indicó que el Estado Mexicano estaba implementando una serie de actividades para afrontar las tres fases posibles, las cuales son:
a) Importación Viral.
b) Dispersión Comunitaria.
c) Fase de Epidemia.

México confirmó el primer caso de SARS-CoV-2 el 27 de febrero de 2020, una persona hospitalizada en el Instituto Nacional de Enfermedades Respiratorias (INER) en la Ciudad de México. En los días siguientes se confirmaron otra serie de pacientes que regresaron de países donde la pandemia se encontraba en una etapa de rápida propagación, es decir, el Estado Mexicano se encontraba dentro de la primera fase, de importación viral.

El primer paciente que murió en México ocasionado por el SARSCoV-2 ocurrió el día 19 de marzo y el 23 del mismo mes se declara la Fase 2 , donde ya había dispersión comunitaria.

Por esta situación se declaraba la implementación del programa nacional denominado “Jornada Nacional de Sana Distancia” el cual contempló las siguientes acciones para contener la propagación de la enfermedad:

I) Susana Distancia. Es decir, mantener un espacio de 1.5 metros entre persona y persona.

2) Suspensión de las clases desde el 23 de marzo hasta el 19 de abril.

3) Suspensión de actividades, eventos y reuniones con más de 100 participantes.

4) Suspensión de actividades laborales que involucren el desplazamiento de personas en todos los sectores de las sociedades.

5) Contratación especial de personal de salud.

6) Activación del Plan DN-III de la Secretaría de la Defensa Nacional y Plan Marina, de la Marina Armada de México.

7) Trabajo coordinado en materia de infraestructura hospitalaria para hacer frente a la pandemia.

8) Protección de personas adultas mayores. 
El 30 de marzo, el Consejo de Salubridad General expidió el acuerdo en el que se declaraba la emergencia sanitaria por causa de fuerza mayor, a la epidemia de la enfermedad generada por el virus SARS-CoV2 y otorgaba a la Secretaría de Salud la potestad para tomar decisiones que posibilitaran atender esta situación. Las cifras oficiales a esta fecha se habían confirmado 1094 personas contagiadas y 28 defunciones en México.

Cabe aclarar que la Jornada Nacional de Sana Distancia se extendió hasta el 30 de mayo y dio paso a la Nueva Normalidad en donde la Secretaría de Salud diseñó una estrategia para la reapertura económica de forma gradual, con base en semáforo epidemiológico, este semáforo se establecerá de forma regional, y con base en el color del mismo se indicarán las actividades que pueden realizarse.

A la fecha que se implementó la Nueva Normalidad, el primero de junio, México tenía de acuerdo con datos de la Secretaría de Salud 93 mil 435 personas infectadas y 10 mil 167 decesos.

\section{CONSIDERACIONES FINALES}

Respecto a las acciones implementadas por el Estado Mexicano para hacer frente a la emergencia sanitaria ocasionada por la enfermedad COVID- I9 se pueden decir las siguientes conclusiones:

I) La implementación de las medidas restrictivas de las libertades, como fueron: el cierre total de las escuelas, la prohibición de las reuniones o eventos de todo tipo incluidos los religiosos, así como la limitación de las labores se hicieron al inicio de la pandemia.

a. Se ha cuestionado que las autoridades federales no trabajaron de forma expedita o se esperaron mucho para implementar ciertas medidas, sin embargo, como se explica, el cierre de actividades se hizo cuando apenas se contaba con 28 defunciones en el territorio, es decir, que las autoridades no esperaron a que estas cifras aumentaran para limitar el ejercicio de las libertades ciudadanas.

b. Esta acción corresponde con los gobiernos de corte autoritario vistos en la investigación de Cheibub, Jean y Przeworski.

2) Por otro lado, es de destacar que, a diferencia de lo que ocurrió tanto con gobiernos autoritarios como democráticos, el gobierno mexicano abrió sus actividades y permitió el ejercicio de libertades ciudadanas cuando el crecimiento del contagio se encontraba en ascenso, pues se implementó la estrategia denominada "Nueva Normalidad" cuando se tenían 93,435 casos confirmados y 10,167. 
a. De esa fecha a septiembre de este año, los casos confirmados son 643,906 y 67,574 defunciones, por lo que la estrategia de apertura se dio a diferencia de otros Estados, democráticos o autoritarios, no cuando existía una disminución de los casos, sino con el aumento.

b. Esto pudiera explicarse a partir de lo indicado por Cronert, en tanto que la economía mexicana no es sólida, y cuenta con un porcentaje importante de personas trabajando en la informalidad; pues de acuerdo con el INEGI, 31.3 millones de personas de 15 años y más se encuentran empleadas en la informalidad.

c. Es decir, México al no tener una economía sólida, no tuvo capacidad para proteger a su población económicamente activa, esto implicó que se tuvieran que abrir ciertos sectores productivos para que las personas pudieran trabajar $y$, con ello, obtener ingresos.

3) A diferencia de lo ocurrido con democracias más consolidadas, donde las poblaciones se están manifestando contra las restricciones a sus libertades, considerando que incluso deben dejar en el individuo la decisión de salir y en él su responsabilidad por si se contagia, en el caso mexicano las restricciones no son nuevas, al ser el epicentro de la pandemia del 2009 por la influenza HINI en donde también se cerraron negocios, escuelas y se limitó la movilización de las personas.

a. Esto, de acuerdo con Cheibub, Jean y Przeworski, indica que México no es una democracia consolidada o con las ideas liberales tan bien cimentadas como otras democracias más asentadas.

b. El debate no se encuentra en la restricción de las libertades, sino en la desconfianza de las instituciones y que la apertura se dio de forma precipitada.

Se implementó en el Estado Mexicano una estrategia basada en la preservación de la Seguridad Pública, y en este sentido, va por encima de la libertad individual $y$, a diferencia de otras democracias donde la libertad individual es el pilar fundamental, aquí no ha generado tanto conflicto.

Frente a los retos de esta nueva enfermedad, efectivamente hay una serie de restricciones a las libertades, sin embargo, en el caso mexicano, no existen debates en torno a las implicaciones que tienen estas sobre la acción individual, pudiera ser una consecuencia del presidencialismo mexicano y de que México tiene pocos años siendo democracia, frente a las democracias más tradicionales. 


\section{REFERENCIAS}

Bobbio, N. (2001). El futuro de la democracia. FCE, México, D.F.

Cheibub, J.A., Hong, J.Y., Przeworski, A. (2020). "Rights and Deaths: Government Reactions to the Pandemic". APSA, Julio 7, 2020.

Cronert, A. (2020) "Democracy, State Capacity, and COVID-19 Related School Closures". APSA, Abril 28, 2020.

Dahl, R. (2006) A preface to Democratic Theory. Expanded Edition. The University of Chicago Press, Chicago, Estados Unidos.

Dahl, R. (1992). La democracia y sus críticos. Paidós, Barcelona, España.

Dahl, R. (2006). La Democracia. Una guía práctica para los ciudadanos. Taurus, México, D.F.

Dworkin, R. (2008). La democracia posible. Principios para un nuevo debate político. Paidós, Barcelona, España, 2008.

Hobsbawm, E., The Age of Revolution. 1789-1848. Random House, Vintage Books, Nueva York, 1996.

INEGI (2020). "Estadísticas a propósito del Día del Trabajo. Datos Nacionales". Comunicado de Prensa num. 166/20.

Ridenhour, B., Kowalik, J. M., \& Shay, D. K. (2015). El número reproductivo básico $\left(R_{0}\right)$ : consideraciones para su aplicación en la salud pública [Unraveling $\mathrm{R}_{0}$ : considerations for public health applications]. Revista panamericana de salud pública = Pan American journal of public health, 38(2), 167-176.

Sanche, S., Lin, Y.T., Xu, C., Romero-Severson, E., Hengartner, N., Ke, R (2020). "Research High Contagiousnees and Rapid Spread of Severe Acute Respiratory Syndrome Coronavirus 2". Emerging Infectious Diseases 26(7), July 2020, p. 1470, 1477 